\title{
Differentiation of clinically non-functioning pituitary adenomas from meningiomas and craniopharyngiomas by positron emission tomography with [18F]fluoro-ethyl-spiperone
}

\author{
Giovanni Lucignani ${ }^{1}$, Marco Losa², Rosa Maria Moresco¹, Angelo Del Sole1, Mario Matarrese1, Valentino Bettinardi1, \\ Pietro Mortini2, Massimo Giovanelli2, Ferruccio Fazio ${ }^{1}$ \\ 1 INB-CNR, Department of Nuclear Medicine, H.S. Raffaele, Milan, Italy \\ 2 Department of Neurosurgery, H.S. Raffaele, Milan, Italy
}

Received 28 February and in revised form 29 April 1997

\begin{abstract}
The differential diagnosis among various types of non-functioning sellar and parasellar tumours is sometimes difficult using currently available methods of morphological imaging. The aim of this study was to define whether assessment of the uptake of $\left[{ }^{18} \mathrm{~F}\right]$ fluoro-ethyl-spiperone (FESP) with positron emission tomography (PET) could be helpful for the differential diagnosis of pituitary adenomas and other parasellar lesions, and for establishing the appropriate therapeutic approach. The population examined comprised 16 patients with the diagnosis of primary tumour of the sellar/parasellar region who were waiting to undergo surgical treatment. The results demonstrated that PET with $\left[{ }^{18}\right.$ F]FESP is a very specific method for differentiating adenomas from craniopharyngiomas and meningiomas. The visual interpretation of images allows such differentiation at approximately $70 \mathrm{~min}$ after tracer injection. Semiquantitative analysis of the dynamic PET data confirmed the results of visual interpretation, demonstrating that the uptake of $\left[{ }^{18} \mathrm{~F}\right] \mathrm{FESP}$ was consistently (i.e. throughout the series) at least two- to threefold higher in non-functioning adenomas than in other parasellar tumours as early as $70 \mathrm{~min}$ after tracer injection, and that it increased still further thereafter. It is concluded that PET with $\left[{ }^{18} \mathrm{~F}\right]$ FESP might be of clinical value in those cases in which the differential diagnosis among various histological types of sellar tumour is uncertain with conventional methods.
\end{abstract}

Key words: Pituitary - Neoplasm - Dopaminergic Receptor

Eur J Nucl Med (1997) 24:1149-1155

Correspondence to: G. Lucignani, Department of Nuclear Medicine, University of Milan, c/o H S. Raffaele, I-20132, Milan, Italy

\section{Introduction}

The most common sellar and parasellar tumours are, in order of frequency, pituitary adenomas, meningiomas, craniopharyngiomas, neurinomas and cordomas. The differential diagnosis of these tumours is currently based on clinical, radiological and endocrine features. The diagnosis of secreting pituitary adenoma is usually obvious because of signs and symptoms characteristic of hormone hypersecretion [1]. Non-functioning pituitary adenomas, as well as meningiomas and craniopharyngiomas, do not cause any specific endocrine syndrome; thus their presence is usually suggested by the evidence of compression of the parasellar nervous structures. In this case, the differential diagnosis among the various types of non-functioning tumours that invade the parasellar region is of the utmost importance because the selection of the appropriate surgical approach may vary depending on the nature of the tumour. The differential diagnosis in these cases is usually achieved by neuroradiological studies, especially by means of magnetic resonance imaging (MRI), a technique that has greatly improved the delineation of pituitary masses. Radiological differential diagnosis, nevertheless, occasionally may be difficult or even impossible using currently available laboratory and imaging tools, in particular in cases of primary parasellar lesions with presentation in the sellar region. At our department diagnostic uncertainty after MRI investigation occurs in about $10 \%$ of patients with hormonally inactive tumours of the sellar region. In such selected cases, the in vivo characterization of the biochemical and functional properties of the tissue, by positron emission tomography (PET) and single-photon emission tomography (SPET), may provide useful information about the nature of the pituitary mass [2].

PET has previously been used for the assessment of pituitary adenomas and other parasellar tumours with several tracers, including $\left[{ }^{11} \mathrm{C}\right]$ methionine, $\left[{ }^{11} \mathrm{C}\right]$ tyrosine, $\left[{ }^{18} \mathrm{~F}\right]$ fluorodeoxyglucose, $\left[{ }^{11} \mathrm{C}\right]$ deprenyl, $\left[{ }^{11} \mathrm{C}\right]-N$-methylspiperone and $\left[{ }^{11} \mathrm{C}\right]$ raclopride [3-7]. 
Some of the methods proposed for the assessment of sellar and parasellar tumours are based on the measurement of biochemical processes that are not specific to any particular type of neoplastic tissue, i.e. the rate of glucose metabolism and protein synthesis. These variables may indicate a neoplastic process when they are abnormally increased or decreased [8]. Such methods have been shown to be useful for visualizing pituitary adenomas, for differentiating between viable neoplastic tissue and scar, and for assessing the response to pharmacological treatment [9].

Other methods are based instead on the use of radiopharmaceuticals that trace processes that take place in the normal and abnormal pituitary tissue, but neither in the other tumours of the sella nor in the nearest surrounding tissue. To this end, the use of $\left[{ }^{11} \mathrm{C}\right]$ deprenyl, a tracer that irreversibly binds to monoamino oxidase $\mathrm{B}$ (MAO-B), has been validated for the differential diagnosis of pituitary adenomas and meningiomas [10].

There is another feature, i.e. the expression of $\mathrm{D}_{2}$ dopamine receptors, that may be useful for the differential diagnosis of pituitary adenomas from meningiomas and other parasellar tumours. However, whereas both $\left[{ }^{11} \mathrm{C}\right]-$ $\mathrm{N}$-methylspiperone and $\left[{ }^{11} \mathrm{C}\right]$ raclopride [11], two antagonists of the $\mathrm{D}_{2}$ dopamine receptors, have been used to visualize pituitary adenomas, the assessment of the binding of PET tracers to $\mathrm{D}_{2}$ dopamine receptors has not been systematically tested and exploited for differentiating pituitary adenomas from other types of parasellar tumours.

This study was aimed at evaluating the possibility of using PET and $\left[{ }^{18} \mathrm{~F}\right]$ fluoro-ethyl-spiperone (FESP), a tracer with high affinity for $\mathrm{D}_{2}$ dopamine receptors, for the differential diagnosis of adenomas and other tumours of the sellar and parasellar region, based on the expression of $\mathrm{D}_{2}$ dopamine receptors by pituitary adenomas, in a group of consecutive patients waiting to undergo surgical treatment.

\section{Materials and methods}

\section{In vivo PET studies}

Patients. The population examined comprised 16 patients (eight males and eight females; mean age 49 years; range: 16-73 years) with the diagnosis of primary tumour of the sellar/parasellar region who were waiting to undergo surgical treatment. The main clinical features of the study population are summarized in Table 1. Endocrine evaluation included measurement of basal levels of $\mathrm{FT}^{3}, \mathrm{FT}^{4}$, testosterone or $17-\beta$-oestradiol, as appropriate, and free urinary cortisol. Moreover, in all patients the response of PRL, TSH, LH and FSH to the i.v. administration of $200 \mu \mathrm{g}$ TRH was assessed. Preoperative neuroradiological assessment included in all cases a skull X-ray and an MRI study of the sella. Based on radiological, clinical and endocrine features, seven patients had a presurgical diagnosis of non-functioning pituitary adenoma, three of meningioma, and three of craniopharyngioma; in the remaining three subjects the presurgical diagnosis was uncertain (see case reports). All subjects underwent a PET study with $\left[{ }^{18}\right.$ F]FESP). The PET study was approved by the Ethical Committee of the San Raffaele Hospital. Participation in the study was voluntary and written informed consent was obtained from each subject.

Radiochemistry. No-carrier-added aqueous [ $\left.{ }^{18} \mathrm{~F}\right]$ fluoride was produced with an ${ }^{18} \mathrm{O}(\mathrm{p}, \mathrm{n})^{18} \mathrm{~F}$ nuclear reaction by proton bombardment of an ${ }^{18} \mathrm{O}$-enriched water target, with a CTI/Siemens RDS 112 cyclotron (Siemens/CPS, Knoxville, Tenn., USA). The synthesis of $\left[{ }^{18} \mathrm{~F}\right] \mathrm{FESP}$ was carried out according to the method of Satyamurthy et al. [12] with minor modifications of the HPLC purification procedure (ammonium acetate $0.025 \mathrm{M} \mathrm{pH} 4.8 / \mathrm{CH}_{3} \mathrm{CN}$,

Table 1. Clinical data in 16 patients operated on for a lesion of the sellar region

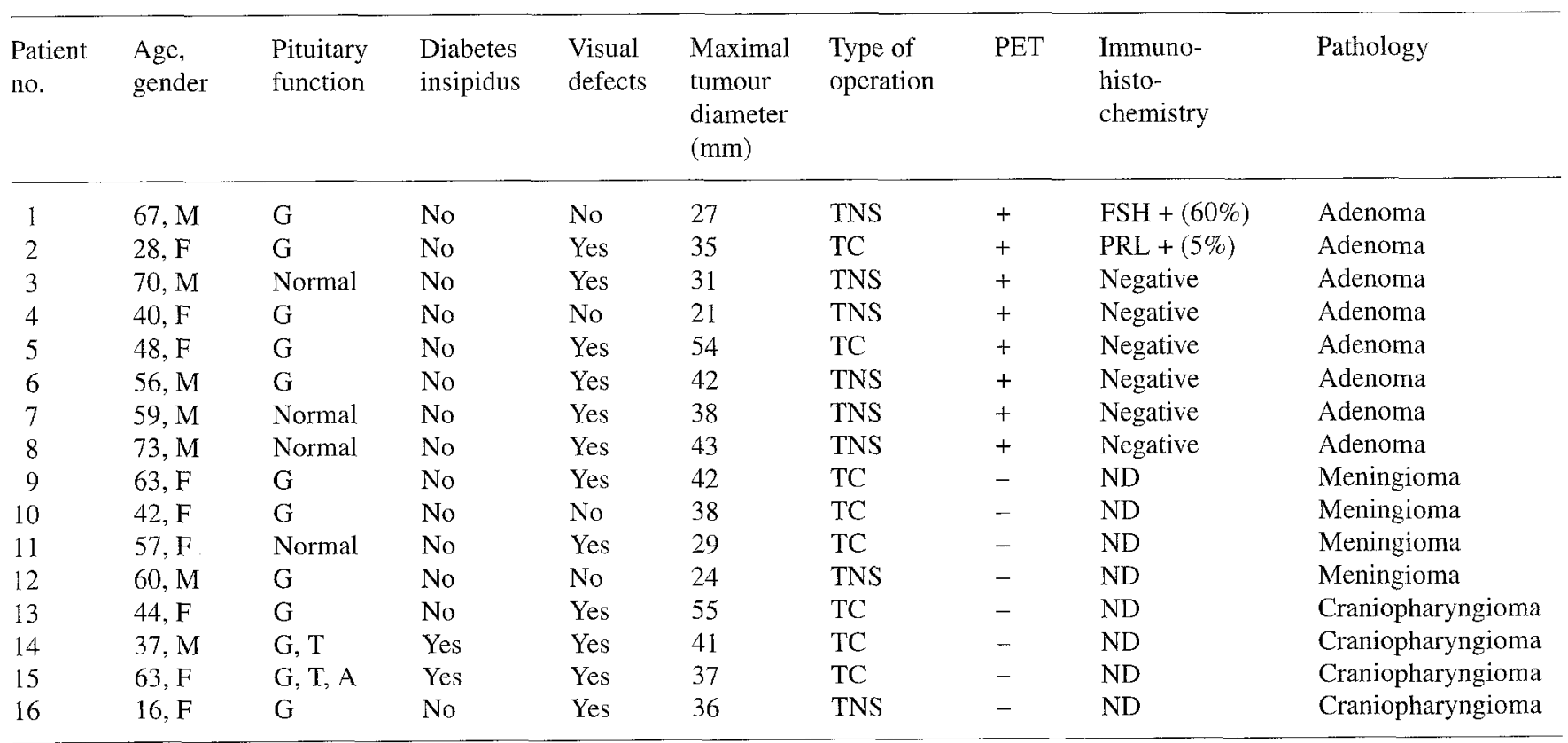

G, Hypogonadism; T, hypothyroidism; A, hypoadrenalism; TNS, trans-sphenoidal; TC, transcranial; ND, not determined 
$40 / 60 \mathrm{vol} / \mathrm{vol}$; viosil C18 $10-\mu \mathrm{m}$ column; flow rate $10 \mathrm{ml} / \mathrm{min}$ ). The resulting product was dissolved in a solution of saline containing 5\% ethanol and passed through a Gelman acrodisc sterile filter into a sterile vial. The radiochemical purity of the tracer produced was higher than $96 \%$. The specific activity, determined by HPLC analysis using a U.V. detector, ranged between 5 and $10 \mathrm{Ci} / \mu$ mole. The sterility and presence of pyrogen, was tested for each preparation by bacteriological analysis and by the limulus amebocyte lysate test.

PET studies. $\left[{ }^{18} \mathrm{~F}\right] \mathrm{FESP}$ PET studies were performed with either a four-ring (ECAT-931/04-12; Siemens/CPS, Knoxville, Tenn., USA) or an 18-ring (GE-Advance; General Electric Medical System, Milwaukee, Wis., USA) whole-body positron emission tomograph. Patients were positioned on the scanner bed with their heads immobilized in the scanner head holder. In order to centre the lesion inside the field of view of the tomograph, positioning of the patient's head was achieved with the aid of laser beams and on the basis of MRI and computed tomography (CT) images. One 15-min transmission scan was carried out with an external germanium-68 ring source. At the end of the transmission scan, patients received an intravenous injection of $120 \mu \mathrm{Ci} / \mathrm{kg}$ of [ $\left.{ }^{18} \mathrm{~F}\right] \mathrm{FESP}$. After tracer injection, sequential scans were acquired. Simultaneous acquisition of data from seven transaxial planes (four direct and three cross planes; slice thickness $6.75 \mathrm{~mm}$ ) parallel to the orbitomeatal line and covering an axial field of view of $5.4 \mathrm{~cm}$ was carried out with the ECAT tomograph. Data from 35 transaxial planes (18 direct and 17 cross planes; slice thickness $4.25 \mathrm{~mm}$ ) parallel to the orbitomeatal line and covering an axial field of view of $15.2 \mathrm{~cm}$ were collected with the GE-Advance-tomograph. Scanning proceeded according to the following schedule: five scans of $1 \mathrm{~min}$ each followed by five scans of $2 \mathrm{~min}$ each and 21 scans of 5 min each. The total scanning time after tracer injection was $70 \mathrm{~min}$ in all 16 patients. Patient compliance allowed us to prolong the study to $90 \mathrm{~min}$ in $12 / 16$ subjects, and to $120 \mathrm{~min}$ in $9 / 16$ subjects. Image reconstruction was performed using a filtered back-projection algorithm with an Hann filter (cut-off frequency 0.5 cycles/pixel) for the ECAT machine, while for the GE-Advance a Hanning filter (cut-off frequency $6.4 \mathrm{~mm}$ ) was used; under these conditions the spatial resolution in the image plane was $\sim 8.5 \mathrm{~mm}$ full-width at half-maximum; images were reconstructed on a $128 \times 128$ matrix with a pixel size of $1.6 \mathrm{~mm}$. Correction for attenuation of the $511-\mathrm{keV} \gamma$-rays by the tissue was performed with the coefficients obtained from the measured trasmission scan.

Histological studies. All patients underwent surgical treatment and histological examination of the tissue specimens obtained at the time of surgery. For light microscopy, specimens of tumour tissue were fixed in $10 \%$ buffered formalin and embedded in paraffin. Sections of 4-6 $\mu \mathrm{m}$ thickness were stained with haematoxylin-eosin and the PAS technique. Immunohistochemistry was performed in pituitary adenomas, using the avidin-biotin-peroxidase complex method. Paraffin sections of 4-6 $\mu \mathrm{m}$ thickness were immunostained for GH, PRL, TSH, ACTH, LH and FSH with commercially available specific rabbit antisera.

Data analysis. Reconstructed images were transferred to a SUN (SPARC) workstation for image processing.

Visual interpretation of PET images was carried out by three physicians unaware of the type of tumour affecting each patient. Each physician was required to visually interpret the sequence of timed PET images of each patient and to score each study as either positive or negative for the presence of abnormal tracer up- take in the pituitary and surrounding tissue at the time of the last scanning. After the initial evaluation, consensus was achieved by collegial examination.

For semiquantitative analysis the cerebellum, an area substantially devoid of $\mathrm{D}_{2}$ dopamine receptors, was chosen as the reference area to estimate the ratio of tumour-to-brain $(\mathrm{T} / \mathrm{Cb})$ binding of $\left[{ }^{18} \mathrm{~F}\right] \mathrm{FESP}$ to $\mathrm{D}_{2}$ receptors. Measurement of $\left[{ }^{18} \mathrm{~F}\right] \mathrm{FESP}$ uptake was carried out on PET brain images in the region of the tumour and in the cerebellar tissue. Based on either MRI or X-ray CT, irregular regions of interest (ROIs) encompassing the lesion and the cerebellar tissue were drawn on the PET images of the final emission scan. Images from the final emission scan were then transferred to the images from each of the other emission scans to obtain the time course of total radioactivity in each ROI. Data were corrected for the physical decay of the ${ }^{18} \mathrm{~F}$ from the time of the injection to the midpoint of the imaging scans.

The ratios of tumour activity to that of cerebellar tissue $(\mathrm{T} / \mathrm{Cb})$ after tracer injection were calculated at discrete time points from the time of injection up to the end of the study.

\section{Results}

Pathology

Histological assay on tumour specimens obtained by surgery confirmed the preoperative diagnosis in the 13 patients in whom the diagnosis had been made before surgery: seven were pituitary adenomas, three were meningiomas and three were craniopharyngiomas. Of the three undiagnosed lesions, one was a pituitary adenoma, one was a meningioma and one was a craniopharyngioma (see case reports).

\section{PET results}

Visual interpretation. An area of increased ${ }^{18} \mathrm{~F}$ uptake, corresponding to the MR images of the lesions, was detectable on the PET images obtained in eight subjects. When the results were examined in relation to the pathology examination, the tracer uptake was confirmed in the patients with adenoma, whereas no tracer uptake was visible in any of the other tumours.

Semiquantitative analysis. The average time course of the tumour-to-brain radioactivity concentration ratio ( $\mathrm{T} / \mathrm{Cb}$ ratio) in the 16 patients examined, is shown in Fig. 1. A progressive increase in the $\mathrm{T} / \mathrm{Cb}$ ratios over time was noted only in the pituitary adenomas, with values between 4 and 8 being reached at $120 \mathrm{~min}$ after tracer injection. $\mathrm{T} / \mathrm{Cb}$ ratios were less than 2 for all patients with parasellar tumours other than adenomas at all times after tracer injection (Fig. 2).

\section{Case reports}

Patient no. 8. A 73-year-old man presented at the emergency department of our hospital complaining of sudden onset of headache and severe visual defect in both eyes. The patient reported that 3 years earlier a cerebral CT 


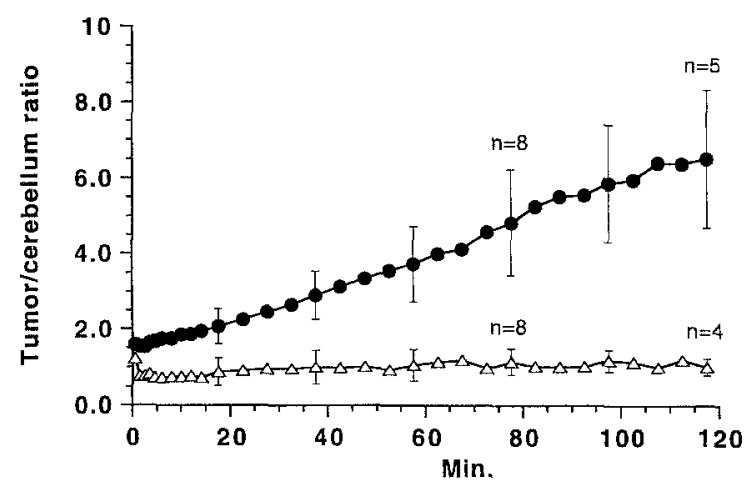

Fig. 1. Time course of the tumour/cerebellum activity ratios of $\left[{ }^{18}\right.$ F]FESP in 16 patients with sellar tumours. Solid circles, pituitary adenomas; open triangles, meningiomas and craniopharyngiomas

Tumor/cerebellum ratio at $70 \mathrm{~min}$

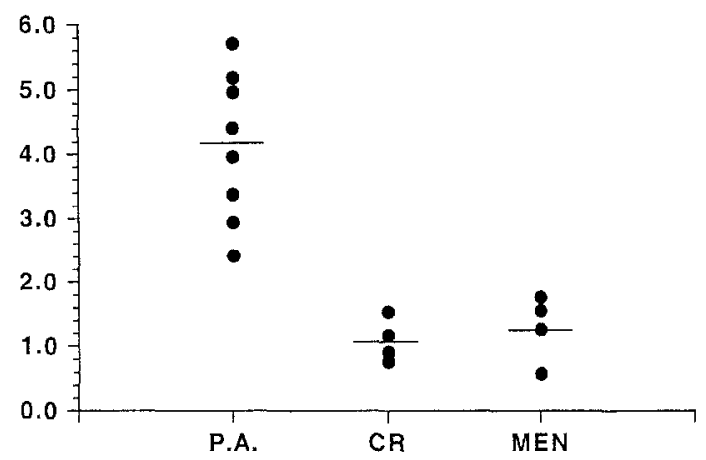

Fig. 2. Tumour/cerebellum activity ratios of [ $\left.{ }^{18} \mathrm{~F}\right] \mathrm{FESP}$ in $16 \mathrm{pa}-$ tients with sellar tumours, $70 \mathrm{~min}$ after i.v. administration of tracer. P.A., Pituitary adenoma; CR, craniopharyngioma; MEN, meningioma

scan, performed because of chronic headache, showed the presence of an intrasellar and slightly suprasellar lesion of the pituitary fossa, compatible with a pituitary adenoma. A neurosurgical consultant did not advise surgical therapy of the lesion, mainly because of the lack of serious symptoms, but recommended neuroradiological examinations at regular intervals. The patient, however, failed to present at follow-up visits. In the ensuing 3 years the patient experienced increasing headache and bilateral worsening of visual acuity. An emergency MRI demonstrated the presence of a huge suprasellar lesion, extending anteriorly toward the frontal lobes, whereas the sella turcica appeared minimally involved. Small areas of hyperintense signal on T1-weighted images were consistent with intratumoural haemorrhage and the abrupt deterioration of vision. Endocrine evaluation did not reveal any hormonal hypersecretion. The MRI picture was more suggestive of a primary suprasellar lesion, possibly a meningioma, but the clinical history was more suggestive of apoplexy of a non-functioning adenoma. The PET study revealed an area of marked uptake of tracer corresponding to the lesion shown by MRI (Fig. 3). A biopsy was performed via the transsphenoidal
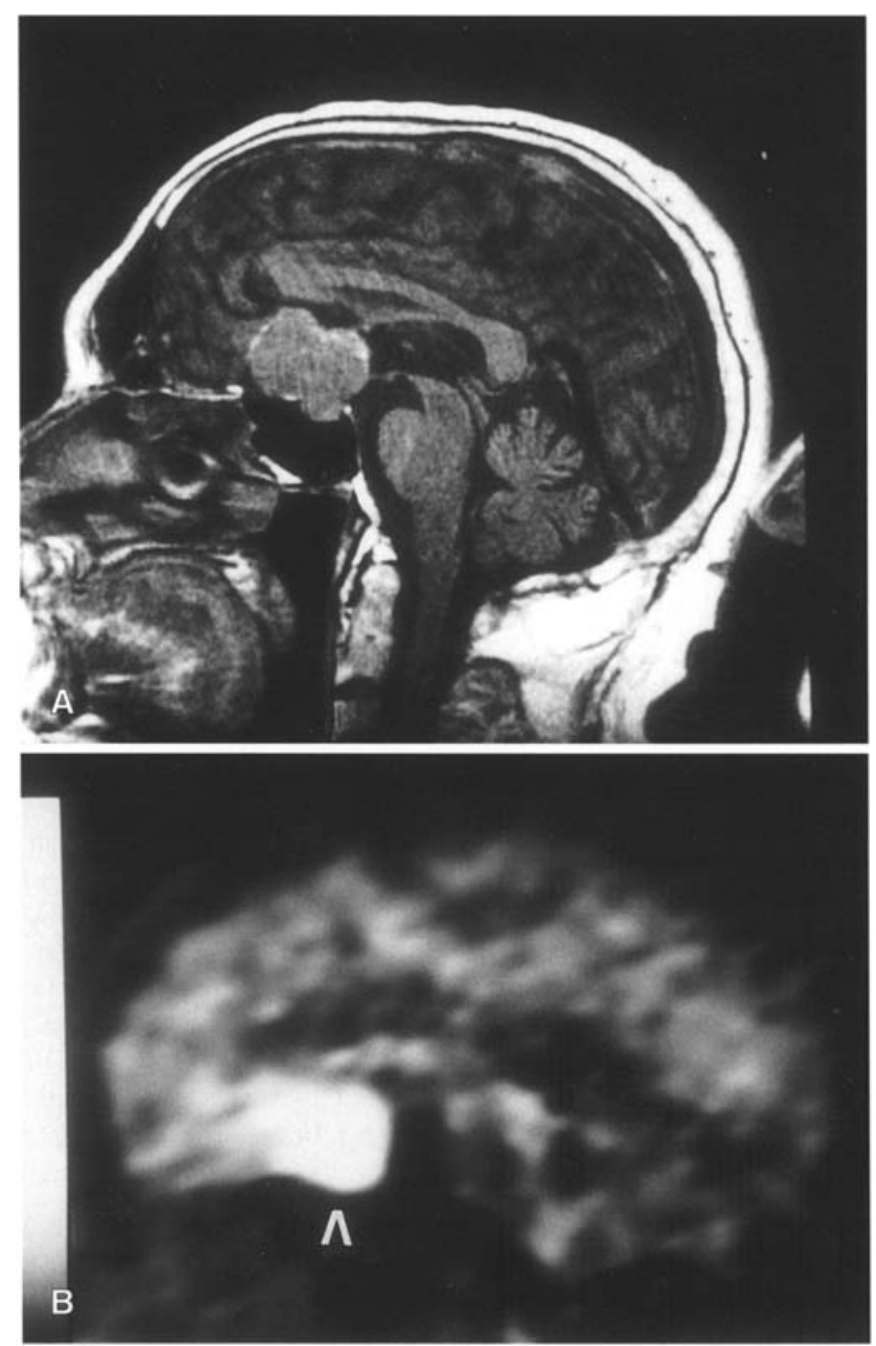

Fig. 3. MRI coronal image (A) and PET transaxial images $(\mathbf{B})$ of the brain in a patient with pituitary adenoma (see case report for patient no. 8). Marked focal tracer uptake is observed on the PET image in an area consistent with the area of lesion observed on MRI

approach: after opening the dura a partially necrotic pituitary adenoma was found and an estimated $50 \%$ of the mass was removed. The presence of a non-functioning pituitary adenoma that did not stain for any pituitary hormone was shown by histology. Postoperatively the patient recovered uneventfully. Slight amelioration of vision was reported during the first days after surgery. Two months after surgery the patient partially regained his visual acuity in both eyes. A repeat MRI 4 months after surgery showed residual adenomatous tissue, but a clear decrease in compression of the surrounding nervous structures. Further treatment of the residual adenoma has still to be planned.

Patient no. 12. A 60-year-old man presented at the emergency department of another hospital because of the sudden onset of diplopia. Neurological examination disclosed palsy of the VIth left cranial nerve. A CT scan re- 
vealed a lesion located in the left cavernous sinus that extended downward into the sphenoid sinus. The patient was then referred to the neurosurgical department of our hospital. Endocrine evaluation did not reveal any significant abnormality. The differential diagnosis was restricted between a meningioma of the cavernous sinus and a pituitary adenoma, especially in the light of the involvement of the sphenoid sinus. MRI of the sellar region confirmed the presence of a mass growing mainly within the left cavernous sinus and extending into the sphenoid sinus. The PET study did not reveal any tracer uptake in the area corresponding to the lesion shown by MRI. The patient was operated on via the trans-sphenoidal approach to obtain a biopsy specimen of the lesion growing in the sphenoid sinus. At operation, firm tissue was detected and biopsied in the sphenoid sinus; the gross appearance of the lesion was suggestive of a meningioma, which was confirmed by pathological examination of the removed tissue. The patient recovered uneventfully. Three months after operation, radiosurgery was performed and the patient experienced a slow resolution of diplopia. At the last follow-up, 12 months after radiosurgery, the patient was well and a repeat MRI showed a small decrease in the size of the residual lesion within the cavernous sinus.

Patient no. 16. A 16-year-old girl was referred to our hospital because of bilateral temporal hemianopia and visual impairment in the left eye. The girl also had primary amenorrhoea, but no diabetes insipidus. Endocrine evaluation revealed an impaired functional reserve of the pituitary. MRI disclosed an intrasellar lesion that extended upward into the suprasellar spaces to compress the optic chiasm and, particularly, the left optic nerve. The lesion, which appeared hypointense on $\mathrm{T} 1$-weighted images, showed a strong signal enhancement after the i.v. administration of paramagnetic contrast only in the peripheral part of the mass. No calcifications were visible on skull X-ray and CT scan. The neuroradiological picture was suggestive of a craniopharyngioma or of a cystic pituitary adenoma. The PET study did not reveal any tracer uptake in the area of the lesion shown by MRI. The patient was operated on via the trans-sphenoidal approach. After opening the dura a typical craniopharyngioma appeared and was entirely removed, except for a rim of tissue in the suprasellar space that was firmly adherent to the dura. Histology confirmed that the lesion was a craniopharyngioma. The patient recovered uneventfully after surgery and treatment with L-thyroxine, hydrocortisone acetate and oestrogen substitution therapy was commenced because of persisting hypopituitarism. Recovery of vision in the left eye and marked improvement of visual fields occurred within 2 months. Postoperative MRI demonstrated the presence of intrasellar pathological tissue that was treated by radiosurgery 6 months after operation.

\section{Discussion}

Differential diagnosis of sellar and parasellar lesions may be of paramount importance when deciding the therapeutic approach to the patient. The most common problem concerns the differentiation between non-functioning pituitary adenomas, craniopharyngiomas and suprasellar meningiomas. The clinical picture of these tumours is aspecific, with the sole exception of diabetes insipidus, which is typical of craniopharyngioma and almost always absent in pituitary adenoma. MRI of the sella has greatly improved the preoperative differentiation of sellar lesions, because of better delineation of anatomical details and differences in signal intensity. Nevertheless, in a few patients a straightforward distinction among the various tumour types is not feasible even after a thorough MRI study.

Functional characteristics of the sellar lesions, such as metabolism and presence of specific types of cellular receptors, can now be investigated in vivo by PET and SPET techniques. Based on the premise that tumours of different origin should possess specific functional characteristics, it was hoped that PET and SPET studies could lead to a clear-cut diagnosis of sellar lesions of uncertain origin. However, so far the results of such studies have in most cases been disappointing. PET with $\left[{ }^{11} \mathrm{C}\right]$ methionine can separate pituitary adenoma from neurinoma [6], but, in our experience, neurinomas can mimic a pituitary adenoma very rarely. The presence of octreotide-binding somatostatin receptors on pituitary tumours allows their in vivo detection after the injection of radionuclide-labelled octreotide. Most of non-functioning adenomas were visualized by ${ }^{111}$ In-DTPA-octreotide in one study [13], but not in another based on the use of ${ }^{123}$ I-Tyr3-octreotide [14]. Moreover, meningiomas also may express somatostatin receptors and can be visualized by somatostatin receptor scintigraphy [15], rendering this method of limited usefulness in the differential diagnosis of sellar lesions.

Promising results were obtained when the content of the enzyme MAO-B was investigated in pituitary adenomas and meningiomas. $\left[{ }^{11} \mathrm{C}\right]$ Deprenyl, a drug that irreversibly binds to MAO-B, was shown to accumulate in adenomas but not in meningiomas [10]. However, a high degree of heterogeneity in the MAO-B concentrations was present among the adenomas examined, causing low tumour-to-brain radioactivity ratios in some adenomas, and thus hampering the interpretation of low $\left[{ }^{11} \mathrm{C}\right] \mathrm{dep}-$ renyl uptake. Our data are consistent with those of Pirker et al., who showed specific binding of 123I-labelled epidepride in a small series of non-functioning pituitary adenomas [16].

Dopamine $\mathrm{D}_{2}$ receptor agonists are used in the treatment of pituitary adenomas. Several tracers bind to the $\mathrm{D}_{2}$ receptors and can be used to visualize such receptors in vivo by emission tomography, but their use has not yet been investigated as a diagnostic tool to differentiate non-functioning pituitary adenomas from other sellar le- 
sions, probably because the former are generally considered deficient in dopamine receptors. In fact, chronic treatment with dopaminergic drugs, such as bromocriptine and quinagolide, is usually ineffective in patients with non-functioning adenomas $[17,18]$, in clear contrast to the high response rate observed in patients with PRL-secreting adenomas [19-21]. In vitro studies clearly demonstrated the presence of high-affinity dopamine receptors in non-functioning pituitary adenomas, although the number of binding sites was lower than in PRL-secreting adenomas and normal pituitary [17, 22]; it must also be noted that a clear role for the $\mathrm{D}_{2}$ receptors in non-functioning adenomas has not yet been defined. Since meningiomas and craniopharyngiomas are not known to possess $\mathrm{D}_{2}$ dopamine receptors, in vivo visualization of the $\mathrm{D}_{2}$ receptor in a pituitary lesion of uncertain origin could permit the differential diagnosis of a non-functioning pituitary adenoma from other non-adenomatous lesions. Our study demonstrates that PET with $\left.{ }^{18}{ }^{18} \mathrm{~F}\right] \mathrm{FESP}$ is a very specific method for the achievement of this aim. All the eight non-functioning adenomas investigated showed uptake of $\left.{ }^{18} \mathrm{~F}\right] \mathrm{FESP}$ that was significantly higher than in the patients with parasellar meningiomas or craniopharyngiomas, without overlap among the different groups. The visual interpretation of images allowed such differentiation at times as early as $70 \mathrm{~min}$ after tracer injection. The semiquantitative analysis of the dynamic data confirmed the results of visual interpretation and demonstrated that the uptake of $\left[{ }^{18} \mathrm{~F}\right] \mathrm{FESP}$ was at least two- to threefold higher in non-functioning adenomas than in other parasellar tumours as early as 70 min after tracer injection, and increased still further thereafter, in contrast to the time course of activity in the other parasellar tumours.

Patients in our study were not selected on the basis of uncertainty of the preoperative diagnosis. In fact, 13 of the study patients had a clinical and neuroradiological picture suggestive of non-functioning adenoma (seven patients), meningioma (three patients) or craniopharyngioma (three patients), whereas only three patients presented with an equivocal preoperative diagnosis. Thus, a larger population with uncertain diagnoses needs to be examined in a prospective study, in which the advantages of the information obtained with $\left[{ }^{18} \mathrm{~F}\right]$ FESP PET with regard to patient management and surgical approach can be addressed. Nevertheless, our results prove the rationale and provide the basis for the use [ $\left.{ }^{18} \mathrm{~F}\right] \mathrm{FESP}$ PET to differentiate non-functioning pituitary adenomas from other lesions of the sellar region, such as meningiomas and craniopharyngiomas, thus allowing a more rational therapeutic approach when the MRI findings are not diagnostic.

\section{References}

Lamberts SWJ, de Herder WW, Kwekkeboom DJ, vd Lely AJ, Nobels FRE, Krenning EP. Current tools in the diagnosis of pituitary tumors. Acta Endocrinol 1993; 129 Suppl 1: 6-12.
De Herder WW, Lamberts SW. Imaging of pituitary tumours. Baillieres Clin Endocrinol Metab 1995; 9: 367-389.

Muhr C, Bergström M, Lundberg PO, Bergström K, Hartvig P, Lundqvist $\mathrm{H}$, Antoni $\mathrm{G}$, Långstöm, B. Dopamine receptors in pituitary adenomas: PET visualization with $\left({ }^{11} \mathrm{C}-\mathrm{N}\right.$-methylspiperone. J Comput Assist Tomogr 1986; 10: 175-180.

Bergström M, Muhr C, Lundberg PO, Bergström K, Lundqvist $\mathrm{H}$, Antoni $\mathrm{G}$, Fasth K-G, Långström $\mathrm{B}$. In vivo study of amino acid distribution and metabolism in pituitary adenomas using

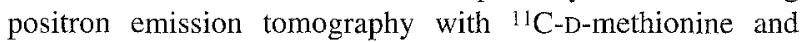
${ }^{11}$ C-L-methionine. J Comput Assist Tomogr 1987; 11: 384389.

De Souza B, Brunetti A, Fulham MJ, Brooks RA, DeMichele D, Cook P, Nieman L, Doppman JL, Oldfield EH, Di Chiro G. Pituitary microadenomas: a PET study. Radiology 1990; 177: 39-44.

Daemen BJ, Zwertbroek R, Elsinga PH, Paans AM, Doorenbos H, Vaalburg W. PET studies with L-[ ${ }^{1}$ C $]$ tyrosine, L[methyl$\left.{ }^{11} \mathrm{C}\right]$ methionine and ${ }^{18} \mathrm{~F}$-fluorodeoxyglucose in prolactinomas in relation to bromocriptine treatment. Eur J Nucl Med 1991; 18: 453-460.

Bergstrom M, Muhr C, Lundberg PO, Langstrom B. PET as a tool in the clinical evaluation of pituitary adenomas. $J \mathrm{NuCl} \mathrm{Med}$ 1991; 32: 610-615.

Report of the Therapeutics and Technology Assessment Subcommitee of the American Academy of Neurology. Assessment: positron emission tomography. Neurology 1991; 41; 163-167.

Muhr C, Bergstrom L, Lundberg PO, Hartman M, Bergström K, Pellettieri L, Långström $\mathrm{B}$. Malignant prolactinomas with multiple intracranial metastases studied with positron emission tomography. Neurosurgery 1988; 22: 374-379.

Bergström M, Muhr C, Jossan S, Lilja A. Nyberg, G. Långström B. Differentiation of pituitary adenoma and meningioma: visualization with positron emission tomography and $\left[{ }^{11} \mathrm{C}\right]-\mathrm{L}-$ deprenyl. Neurosurgery 1992; 30: 855-861.

Muhr C, Bergström M. Positron emission tomography applied in the study of pituitary adenomas. $J$ Endocr Invest 1991; 14 : 509-28.

Satyamurthy N, Barrio JR, Bida GT, Huang SC, Mazziotta JC, Phelps ME. 3-(2'-[18F]fluoroethyl)spiperone, a potent dopamine antagonist: synthesis, structural analysis and in-vivo utilization in humans. Appl Radiat Isot 1990; 4: 113-129.

Krenning EP, Kwekkeboom DJ, Bakker WH, Breeman WAP, Kooij PPM, Oei HJ, van Hagen M, Postema PTE, de Jong M, Reubi JC, Visser TJ, Reijs AEM, Hofland LJ, Koper JW, Lamberts SWJ. Somatostatin receptor scintigraphy with ${ }^{111} \mathrm{In}$ DTPA-D-Phe and ${ }^{123}$ I-Tyr3-octeotride: the Rotterdam experience in more than 1000 patients. Eur $J$ Nucl Med 1993; 20: 716-731.

Faglia G, Bazzoni N, Spada A, Arosio M, Ambrosi B, Spinelli F, Sara $\mathrm{R}$, Bonino $\mathrm{C}$, Lunghi $\mathrm{F}$. In vivo detection of somatostatin receptors in patients with functionless pituitary adenomas by means of a radioiodinated analog of somatostatin ([ $\left.{ }^{123} \mathrm{I}\right] \mathrm{SDZ}$ 204-090). J Clin Endocrinol Metab 1991; 73: 850-856.

Lamberts SW, Krenning EP, Reubi JC. The role of somatostatin and its analogs in the diagnosis and treatment of tumors. Endocr Rev 1991; 12: 450-482.

Pirker W, Riedl M, Luger A, Czech T, Rossler K, Asenbaum S, Angelberger P, Kornhuber J, Deecke L, Podreka I, Brucke T. Dopamine $D_{2}$ receptor imaging in pituitary adenomas using iodine-123-epidepride and SPECT. J Nucl Med 1996; 37: $1931-1937$. 
Bevan JS, Burke CW. Non-functioning pituitary adenomas do not regress during bromocriptine therapy but possess membranebound dopamine receptors which bind bromocriptine. Clin Endocrinol (Oxf) 1986; 25: 561-572.

Bevan JS, Webster J, Burke CW, Scanlon MF. Dopamine agonists and pituitary tumor shrinkage. Endocr Rev 1992; 13: 220-240.

McGregor AM, Scanlon MF, Hall R, Hall K. Effects of bromocriptine on pituitary tumor size. Br Med $J$ 1979; 2: 700-703.

Liuzzi A, Dallabonzana D, Oppizzi G, Verde GG, Cozzi R, Chiodini P, Luccarelli G. Low doses of dopamine agonists in the long-term treatment of macroprolactinomas. $N$ Engl $\mathrm{J} \mathrm{Med}$ 1985; 313: 656-659.

Molitch ME, Elton RL, Blackwell RE, Caldwell B, Chang RJ, Jaffe R, Joplin G, Robbins RJ, Tyson J, Thorner MO. Bromocriptine as primary therapy for prolactin-secreting macroadenomas: results of a prospective multicenter study. $J$ Clin Endocrinol Metab 1985; 60: 698-705.

Koga M, Nakao H, Arao M, Sato B, Noma K, Morimoto Y, Kishimoto S, Mori S, Uozumi T. Demonstration of specific dopamine receptors on human pituitary adenomas. Acta Endocrinol (Copenh) 1987; 114: 592-602. 